\title{
Why Consciousness is primary: epistemological and scientific evidence
}

\author{
Patrizio Tressoldi $^{*}$, Enrico Facco ${ }^{2}$ \\ ${ }^{1}$ Science of Consciousness Research Group, Studium Patavinum - University of Padova, Italy \\ ${ }^{2}$ Studium Patavinum - Department of Neurosciences, University of Padova, Italy
}

[version 5/16/2022]

\begin{abstract}
Three categories of phenomena challenge the hypothesis that consciousness is an epiphenomenon or a byproduct of brain activity:

-the irreducibility of first-person subjective experience to third-person information, e.g., pain and emotions assessment;

-mind-brain-body top-down causation effects, e.g., placebo, hypnosis, meditation, biofeedback;

- many non-ordinary mental expressions, e.g., near-death experiences, nonlocal perception and interaction, mystical experiences.
\end{abstract}

This bulk of evidence suggests that consciousness is primary, requiring a revision of the mindbrain-body relationship and of its metaphysical interpretation.

Keywords: consciousness; qualia; mind-brain interaction; non-ordinary mental experiences

\footnotetext{
${ }^{1}$ Corresponding author: patrizio.tressoldi@ unipd.it
} 


\section{Introduction}

The debate about the nature of consciousness revolves around two opposing theories: a) consciousness is a byproduct or an emergent property of the brain; b) consciousness is primary and manifests some, but not all its characteristics, by using the brain that functions as a filter.

The aim of this opinion paper is to outline the scientific evidence that severely challenge the idea of the consciousness as a byproduct or an emergent property of the brain, but alternatively supports the opposite view that consciousness is primary.

Although ostensibly odd from the materialist standpoint, the idea of the primacy of consciousness is more than thousand years old and runs through the whole history of cultural, religious and philosophical traditions of both the East and the West (e.g., see Indich, 1995; Kastrup, 2018; Walach, 2020), suggesting the need to reappraise it through a metaphilosophical approach (Facco et al. 2021).

Apart from these philosophical interpretations, in the last two decades, a huge amount of scientific evidence has been obtained supporting the primacy of consciousness. The aim of this paper is to outline a summary of these findings that have been mostly skipped in the debate on the mind-brainbody relationship.

We shall summarize the scientific evidence in the three following main categories: i) the irreducibility of qualia or subjective first-person experiences to third-person information; ii) mind topdown effects on brain and body and iii) non-ordinary mental expressions incompatible with brain biological constraints. The first two categories are particularly relevant for all professionals working with diseases and human health.

\section{On the irreducibility of qualia to third-person information}

The role of subjective phenomena, like pain and psychological unease, is a topic of paramount importance in both everyday life and clinical practice. Despite the huge development of pain management in the past decades, pain remains elusive, and many patients remain in the middle of the ford struggling between low drug efficacy and their overuse. A reason for pain elusiveness is its nature as a subjective phenomenon, escaping the meshes of the objectivist, mechanistic-reductionist net prevailing in medicine. Pain is not only a symptom but an essential aspect of life, and its noetic and autonoetic components play a key role in the development of the concepts of pleasure-unpleasure and tolerable or intolerable. The quality of pain and suffering also depend on what the pain means to the patient, while its nature of subjective experience makes physicalists hypotheses untenable (Facco, 2021).

The quality, intensity and meaning of every sensation, emotion, feeling and experience can be accessed only through the first and second person perspectives (1PP and 2PP, respectively), making the neurobiological third person perspective (3PP) unsuitable to properly understand them (Tressoldi, Facco, \& Lucangeli, 2017). For example, despite the detailed knowledge of neurophysiological and neurochemical mechanisms of pain (Tan \& Kuner, 2021), its intensity can be assessed only by a patient's 1PP report, using open questions or structured methods, e.g. the McGill pain questionnaire and the Visual Analog Scale (Caraceni et al., 2002). Given its subjective nature, pain evaluation is 
much more uncertain in children and patients with cognitive impairments, calling for an empathic approach aimed at guessing the patient's pain experience. A clear example of the fallacy of a narrow positivist-objectivist approach is the last century's prevailing opinion (also affected by naïve realism) that newborns and infants were insensitive to pain and neither needed anesthesia for surgery nor postoperative pain treatment (Lipmann, Nelson, \& Emmanouilides, 1976). Fortunately, this merciless behavior is currently unacceptable, but pain in children has been generally underestimated for decades (Hamers, Abu-Saad, van den Hout \& Halfens, 1998), where the lack of communication of their experience was naively taken for the absence of pain, inadvertently turning medicine into torture.

The same applies to all types of emotions (e.g., those engendered by a painting, piece of music a movie, etc.), where their valence, experience and meaning cannot be comprehended by the analysis of their neural correlates unless 1PP and 2PP are taken into account (Bradeley, Margaret; Lang, 2000; Kurdi, Lozano, \& Banaji, 2017; Tressoldi, Facco, \& Lucangeli, 2017).

In short, a narrow materialist-reductionist perspective is a valuable method to check the relationship between physical facts, but should not be turned into ontology, i.e., that is true and worth being studied and understood only what is compatible with it. Scientific reductionism is blind to qualia and, thus, cannot properly explain the role of subjective experience in the world; indeed, should the process of reduction from consciousness to its neural correlates be completed, these experiences and consciousness itself would be missing.

\section{On the mind top-down causation}

Scientific reductionism, being based on a materialist view, only accepts the one-way reduction from mind to brain and, thus, a bottom-up hierarchy. Nevertheless, this stance is axiomatic in nature and its truthfulness is not demonstrated. On the other hand, a top-down causation is not surprising when the mind-brain-body is defined as an inseparable, highly interconnected unit, i.e., a dynamic complex system able to adapt and evolve over time according to its mutual relationship with the environment.

The top-down causation seems clear in everyday experience when one simply decides to move because of one's intention to do it and does not feel or believe to be driven by one's legs or brain circuitry.

In the following, we will present evidence of clear top-down mental effects not only on brain activity, but even on body physiology and anatomy.

\section{Placebo and Nocebo}

Actually, a wealth of data shows the scientific and clinical relevance of placebo and nocebo responses (Benedetti, 2020; Rief \& Petrie, 2016; Tracey, 2010). The former, wrongly considered as a "false" therapy in the past, may yield long-lasting effects and can improve several disorders besides pain, such as depression and Parkinson's disease (Diederich \& Goetz, 2008; Rutherford et al., 2017).

Limiting oneself to seek for design methods able to prevent a high placebo response (Piercy, Sramek, Kurtz, \& Cutler, 1996) may undoubtedly help improve the assessment of drug effectiveness, but the neglect of the clinical relevance of placebo it tantamount to throwing the baby out with the bath water. On the other hand, a nocebo may cause adverse events in 30-80\% of patients in the control group in the randomized controlled trials (de la Cruz, Hui, Parsons, \& Bruera, 2010; Dimitriadis \& Zis, 2017; Lombardi, Gargioni, Canonica, \& Passalacqua, 2008; Mondaini et al., 2007; Penson et al., 2018; Zis, Hadjivassiliou, Sarrigiannis, Jenkins, \& Mitsikostas, 2018). 
What is outstanding is that beliefs, expectations, hope, as well as words and rituals, that is, all what is made of pure mental stuff, including psychosocial components, can strongly affect the meaning of pain and its tolerability as well as change the patterns of brain activation/deactivation, yielding effects similar to those induced by drugs (Barbiani \& Benedetti, 2020) and even surgical-like effects similar to the real surgical ones (Banik, 2020).

\section{$\underline{\text { Hypnosis and Meditation }}$}

Hypnosis is a valuable tool for patient empowerment and self-transformation (Spiegel, 2013) and has shown the capacity to decrease pain perception up to the level of surgical analgesia (Facco, Pasquali, Zanette, \& Casiglia, 2013; Facco, Bacci, \& Zanette, 2021). For instance, hypnotic analgesia is the result of an intentional introspective mental activity able to alter the pain neuromatrix preventing the activation of the somatosensory cortex (Casiglia et al., 2020) and prevent stress-related cardiovascular reactions (Casiglia et al., 2012). Hypnotic suggestions to feel pain or an unpleasant sensation specifically yield the activation of somatosensory cortex or anterior cingulate cortex (ACC), respectively (Rainville, Carrier, Hofbauer, Bushnell, \& Duncan, 1999). Likewise, hypnotically induced pain, but not pain imagined in conditions of ordinary consciousness, activates the pain neuromatrix including the thalamus, ACC, insula and prefrontal, and parietal cortices, a pattern similar to pain yielded by nociceptive stimuli (Derbyshire, Whalley, Stenger, \& Oakley, 2004).

Likewise, several studies report on the beneficial effects of meditation on pain as well as on the genetic and immune system (Househam, Peterson, Mills, \& Chopra, 2017; Jacobs et al., 2011; Schakel et al., 2019; Zeidan et al., 2011), showing a top-down causal influence of mind not only on brain but even on body functioning.

This bulk of clinical and experimental studies clearly endorse the reality of the top-down control of mind over brain and body. This has led to medicine having neglected the role of the mind in both health and disease, taking the patient for a powerless carrier of an organic diseases. Instead, the capacity of the mind to control the brain and the body is clear-cut and immediately given as real fact: it is a simple aspect of the physiology of the mind-brain-body rejected a priori by materialism. Of course, the top-down control is usually much less than optimal in everyday life; it is a huge, unfulfilled potential related to the development and full realization of self and a full self-mastery.

\section{$\underline{\text { Biofeedback }}$}

Biofeedback is the capacity to voluntarily control and mentally modify neural (e.g., EEG frequencies) and physiological signals (e.g., heart rate, electrodermal activity, electromyography, etc.). In essence it is a top-down mind-brain/body activity with a wide range of practical application from neuromuscular rehabilitation (Giggins, Persson, \& Caulfield, 2013; Tamburella et al., 2019), to mental disorders (Alneyadi, Drissi, Almeqbaali, \& Ouhbi, 2021) and as tools to allow locked-in patients to use a spelling device (Chaudhary et al., 2022).

Whereas biofeedback could also be implemented without a voluntary control (Liu et al., 2007; Marandi, Madeleine, Omland, Vuillerme, \& Samani, 2019), the classical biofeedback procedure requires the participants to consciously detect and alter mentally the specific physiological signals in order to increase or decrease specific parameters (e.g., frequency, duration, etc.) in order to achieve the desired 
characteristics of the signal coupled with the behavioral or physiological outcome. In simple words, the mind of the participants can modify some specific physiological signals by way of a top-down (mindmatter) influence.

\section{On the non-ordinary mental expressions incompatible with brain biological constraints}

The primacy of consciousness is strongly evident by Non-Ordinary Mental Expressions or Experiences (NOMEs), a name coined to indicate non-pathological, ostensibly odd phenomena. It is a topic endowed with deep epistemological implications due to their deviation from the accepted Weltbild (Facco, Agrillo, \& Greyson, 2015; Facco, Fracas, \& Tressoldi, 2021). Among these, Neardeath experiences (NDEs) have defied all available reductionist interpretations so far (Facco \& Agrillo, 2012; Martial, Cassol, Laureys, \& Gosseries, 2020; Testoni, Facco, \& Perelda, 2017), while the uncommon but well described cases of witnessed NDEs challenge the view of consciousness as a plain epiphenomenon of brain circuitry (Parnia et al., 2014; Woollacott \& Peyton, 2021). No less baffling are the visions reported by NDErs blind since birth (Ring, Valarino, \& Connecticut, 1998).

Similarly, spiritual/mystic and nondual consciousness experiences (de Castro, 2017; Facco, Lucangeli, \& Tressoldi, 2019; Mills, Barsotti, Blackstone, Chopra, \& Josipovic, 2020; Taves, 2020) have also been reported as not compatible with the brain neurophysiological constraints.

Furthermore, the increasing evidence of puzzling nonlocal perceptions (e.g. acquisition of information beyond the constraints of sensory organs) and nonlocal interactions, e.g. interaction at distance with biological (Radin, Schlitz, \& Baur, 2015; Roe, Sonnex, \& Roxburgh, 2014) and physical objects (Radin, Wahbeh, Michel, \& Delorme, 2021), traditionally classified as paranormal (Cardeña, 2018; Cardeña, Lynn, \& Krippner, 2017; Tressoldi \& Storm, 2021; Walach, Tressoldi, \& Pederzoli, 2016), challenges their reducibility to known brain circuitry

These facts cannot be rejected on the basis of their ostensible incompatibility with a physicalist interpretation of mind and consciousness.

\section{Concluding remarks}

The above scientific evidence strongly suggest that consciousness is not a plain, passive epiphenomenon of brain circuitry; rather, it supports a bidirectional causation from brain to mind and vice versa. For example, non-invasive brain stimulations and psychotropic agents as well as brain injuries undoubtedly result in the modification of mental contents and activity, but the above mentioned scientific evidence clearly shows that conscious and unconscious mental contents can alter brain circuitry and body physiology as well, yielding outstanding effects like placebo, nocebo and hypnotic analgesia.

Interestingly, a two-way causation is more compatible with the ancient non-dualist paradigm of Heraclitus, Parmenides and Taoism (Lau Tzu, 2009) holding the complementarity and cogeneration of opposites, rather than the classic Western thought.

Certainly, the available data do not definitively prove the primacy of consciousness, but they are strong enough to conceive the mind-brain-body-environment as an inseparable dynamic, interrelated complex system, endowed with reciprocal bidirectional causation and co-evolution; here, 
"reality", as it is known, is a creation of the conscious representations and interpretations of all information obtained through the filter of the brain and sensory organs. In other words, the outer world as we know it is an inseparable co-creation of phenomena per se and the mind-brain. It is the world 3 according to the theory of the Three Worlds, introduced by Popper and Eccles (Popper, 1972; Popper \& Eccles, 1977), an interactionist view aiming to overcome the inflexible dichotomies yielded by the materialist and dualist metaphysical stances. The criticism raised to the Popper's concept of rational knowledge can be exceeded by modified, neurophenomenological theory or the three worlds, where world 2 is the mind-brain unit (the transducer and processor of inputs form world 1) and world 3 is the world of mind, including all its contents); this allows to broaden our view in order to encompass both the physical and the mental worlds and merge them in a whole (Facco, Fracas, Tagliagambe, \& Tressoldi, 2021).

The need to move towards a wider monist view exceeding the limits of the traditional monist materialist and dualists stances and encompassing both the inner and outer worlds has been increasingly advocated in the past years and named by different authors neutral monism, reflexive monism, dual aspect monism, holomonism or whole-monism (Atmanspacher, 2012; Facco, Lucangeli, \& Tressoldi, 2017; Solms \& Panksepp, 2012; Stubenberg, 2018; Walach, 2020; Keppler \& Shani, 2020; Velmans, 2021).

Of course, reductionism remains a valuable and powerful method for the solution of Chalmers' easy problem (Chalmers, 1998). Yet, it is only a method and, as such, it cannot be turned into ontology, i.e., the idea that only what is compatible with it exists and is worth being studied.

We think that the ongoing debate between materialist monists and dualists in the science of consciousness has been affected by narrow, inflexible metaphysical assumptions, where a priori adopted axioms and ontologized entities have been incorrectly imposed on the observed reality. Indeed, what is immediately given is the Dasein ("being there" or "presence", to use Heidegger's words) which is made of the stuff of consciousness. Neither the perception of the outer world nor any Weltbild could exist without consciousness and not even science, which lives in the world of consciousness as a product of mind (the Popper and Eccles' World 3; Popper \& Eccles, 1977) yielding valuable models of the outer world according to the adopted paradigm (Tagliagambe, Fracas \& Facco 2020).

The debate on the mind-brain-body-world relationship cannot any longer skip the increasing evidence provided by studies on hypnosis, meditation, placebo, nocebo, pain and other subjective relevant clinical phenomena as well as the whole spectrum of non ordinary mental experiences. Otherwise, there is a high risk of deviation from reality engendered by the closure of investigated phenomena within the limits of selected facts, theories and mental cathegories, leading to what Edgar Morin has defined as nothing crazier than the delusion of abstract coherence (Morin, 2011). 


\section{Nature of Consciousness}

Acknowledgments: We thank the Proof-Reading-Service for English revision.

Declarations of interest: none 


\section{References}

Alneyadi, M., Drissi, N., Almeqbaali, M., \& Ouhbi, S. (2021). Biofeedback-based connected mental health interventions for anxiety: Systematic literature review. JMIR MHealth and UHealth. https://doi.org/10.2196/26038

Atmanspacher, H. (2012). Dual-Aspect Monism a la Pauli and Jung. Journal of Consciousness Studies, 19(9-10), 96-120.

Banik, R. K. (2020). Therapeutic benefits of placebo surgery and challenges in neuromodulation research. Pain, 161(8), 1937-1939. https://doi.org/10.1097/j.pain.0000000000001910

Benedetti, F. (2020). Placebo Effects (3rd ed.). Oxford: Oxford University Press.

Bradeley, Margaret; Lang, P. J. (2000). Measuring Emotion: Behavior, Feeling and Physiology. (D. R. N. L. Lane, Ed.). Oxford: Oxford Universiy Press.

Caraceni, A., Cherny, N., Fainsinger, R., Kaasa, S., Poulain, P., Radbruch, L., ... Combes, J. . (2002). Pain measurement tools and methods in clinical research in palliative care: recommendations of an Expert Working Group of the European Association of Palliative Care. Journal of Pain and Symptom Management, 23(3), 239-255. https://doi.org/10.1016/S0885-3924(01)00409-2

Cardeña, E. (2018). The experimental evidence for parapsychological phenomena: A review. American Psychologist, 73(5), 663-677. https://doi.org/10.1037/amp0000236

Cardeña, E., Lynn, S. J., \& Krippner, S. (2017). The Psychology of Anomalous Experiences: A Rediscovery. Psychology of ConsciouTheory, Research, and Practice. https://doi.org/http://dx.doi.org/10.1037/cns0000093

Casiglia, E., Tikhonoff, V., Giordano, N., Andreatta, E., Regaldo, G., Tosello, M. T., ... Facco, E. (2012). Measured outcomes with hypnosis as an experimental tool in a cardiovascular physiology laboratory. International Journal of Clinical and Experimental Hypnosis, 60(2), 241-261. https://doi.org/10.1080/00207144.2012.648078

Casiglia, E., Finatti, F., Tikhonoff, V., Stabile, M. R., Mitolo, M., Albertini, F., ... Venneri, A. (2020). Mechanisms of hypnotic analgesia explained by functional magnetic resonance (fMRI). The International Journal of Clinical and Experimental Hypnosis, 68(1), 1-15. https://doi.org/10.1080/00207144.2020.1685331

Chalmers, D. J. (1998). The problems of consciousness. Adv.Neurol., 77(0091-3952 (Print)), 7-16.

Chaudhary, U., Vlachos, I., Zimmermann, J. B., Espinosa, A., Tonin, A., Jaramillo-Gonzalez, A., ... Birbaumer, N. (2022). Spelling interface using intracortical signals in a completely locked-in patient enabled via auditory neurofeedback training. Nature Communications 2022 13:1, 13(1), 19. https://doi.org/10.1038/s41467-022-28859-8

de Castro, J. M. (2017). A model of enlightened/mystical/awakened experience. Psychology of Religion and Spirituality, 9(1), 34-45. https://doi.org/10.1037/rel0000037 
de la Cruz, M., Hui, D., Parsons, H. A., \& Bruera, E. (2010). Placebo and nocebo effects in randomized double-blind clinical trials of agents for the therapy for fatigue in patients with advanced cancer. Cancer, 116(3), 766-774. https://doi.org/10.1002/cncr.24751

Derbyshire, S. W., Whalley, M. G., Stenger, V. A., \& Oakley, D. A. (2004). Cerebral activation during hypnotically induced and imagined pain. Neuroimage, 23(1053-8119 (Print)), 392-401.

Diederich, N. J., \& Goetz, C. G. (2008). The placebo treatments in neurosciences: New insights from clinical and neuroimaging studies. Neurology, 71(1526-632X (Electronic)), 677-684.

Dimitriadis, P., \& Zis, P. (2017). Nocebo Effect in Menière's Disease: A Meta-analysis of Placebocontrolled Randomized Controlled Trials. Otology \& Neurotology (Vol. 38). https://doi.org/10.1097/MAO.0000000000001555

Facco, E. (2021). Pain, the uknown: epistemological issues and related clinical implications. Minerva Anestesiologica. https://doi.org/10.23736/S0375-9393.21.15920-6

Facco, E., \& Agrillo, C. (2012). Near-death experiences between science and prejudice. Frontiers in Human Neuroscience, 6(art. 209), 1-7. https://doi.org/10.3389/fnhum.2012.00209

Facco, E., Agrillo, C., \& Greyson, B. (2015). Epistemological implications of near-death experiences and other non-ordinary mental expressions: Moving beyond the concept of altered state of consciousness. Medical Hypotheses, 85(1), 85-93. https://doi.org/10.1016/j.mehy.2015.04.004

Facco, E., Al Khafaji, B. E. E., \& Tressoldi, P. (2019). In search of the true self. Journal of Theoretical and Philosophical Psychology, 39(3), 1-24. https://doi.org/10.1037/teo0000112

Facco, E., Bacci, C., \& Zanette, G. (2021). Hypnosis as sole anesthesia for oral surgery: The egg of Columbus. The Journal of the American Dental Association. https://doi.org/10.1016/J.ADAJ.2021.04.017

Facco, E., Fracas, F., Tagliagambe, S., \& Tressoldi, P. (2021). On the nature and role of Consciousness: is it time to move towards a metaphilosophical and metascientific approach? MindRxiv, 1-25.

Facco, E., Fracas, F., \& Tressoldi, P. (2021). Moving beyond the concept of altered state of consciousness: The Non-Ordinary Mental Expressions (NOMEs). Advances in Social Sciences Research Journal, 8(3), 615-631. https://doi.org/10.14738/assrj.83.9935

Facco, E., Lucangeli, D., \& Tressoldi, P. (2017). On the Science of Consciousness: Epistemological Reflections and Clinical Implications. EXPLORE: The Journal of Science and Healing, 13(3), 163-180. https://doi.org/10.1016/j.explore.2017.02.007

Facco, E., Lucangeli, D., \& Tressoldi, P. (2017). On the Science of Consciousness: Epistemological Reflections and Clinical Implications. https://doi.org/10.1016/j.explore.2017.02.007

Facco, E., Lucangeli, D., \& Tressoldi, P. (2019). Dr. A.M.-A case of a modern mystic? Implications for psychology and medicine. Spirituality in Clinical Practice, 6(1), 44-65. https://doi.org/10.1037/scp0000171 
Facco, E., Pasquali, S., Zanette, G., \& Casiglia, E. (2013). Hypnosis as sole anaesthesia for skin tumour removal in a patient with multiple chemical sensitivity. Anaesthesia, 68(9), 961-965. https://doi.org/10.1111/anae.12251

Giggins, O. M., Persson, U. M. C., \& Caulfield, B. (2013). Biofeedback in rehabilitation. Journal of NeuroEngineering and Rehabilitation. https://doi.org/10.1186/1743-0003-10-60

Hamers, J. P., Abu-Saad, H. H., van den Hout, M. A., \& Halfens, R. J. (1998). Are children given insufficient pain-relieving medication postoperatively? J.Adv.Nurs., 27(0309-2402 (Print)), 3744.

Househam, A. M., Peterson, C. T., Mills, P. J., \& Chopra, D. (2017, September 1). The Effects of Stress and Meditation on the Immune System, Human Microbiota, and Epigenetics. Advances in Mind-Body Medicine.

Indich, W. M. (1995). Consciousness in Advaita Vedanta. Motilal Banarsidass Publisher.

Jacobs, T. L., Epel, E. S., Lin, J., Blackburn, E. H., Wolkowitz, O. M., Bridwell, D. A., ... Saron, C. D. (2011). Intensive meditation training, immune cell telomerase activity, and psychological mediators. Psychoneuroendocrinology, 36(5), 664-681. https://doi.org/10.1016/j.psyneuen.2010.09.010

Kastrup, B. (2018). The Universe in Consciousness. Journal of Consciousness Studies, 25(5-6), 125155.

Keppler, J., \& Shani, I. (2020). Cosmopsychism and consciousness research: a fresh view on the causal mechanisms underlying phenomenal states. Frontiers in Psychology, 11, 371.

https://doi.org/10.3389/fpsyg.2020.00371

Kurdi, B., Lozano, S., \& Banaji, M. R. (2017). Introducing the Open Affective Standardized Image Set (OASIS). Behavior Research Methods, 49(2), 457-470. https://doi.org/10.3758/s13428-016-07153

Liu, D. S., Chang, W. H., Wong, A. M. K., Chen, S. C., Lin, K. P., \& Lai, C. H. (2007). Development of a biofeedback tilt-table for investigating orthostatic syncope in patients with spinal cord injury. Medical and Biological Engineering and Computing, 45(12), 1223-1228. https://doi.org/10.1007/S11517-007-0272-0/FIGURES/3

Lombardi, C., Gargioni, S., Canonica, G. W., \& Passalacqua, G. (2008). The nocebo effect during oral challenge in subjects with adverse drug reactions. European Annals of Allergy and Clinical Immunology, 40, 138-141.

Marandi, R. Z., Madeleine, P., Omland, Ø., Vuillerme, N., \& Samani, A. (2019). An oculometricsbased biofeedback system to impede fatigue development during computer work: A proof-ofconcept study. PLOS ONE, 14(5), e0213704. https://doi.org/10.1371/JOURNAL.PONE.0213704

Martial, C., Cassol, H., Laureys, S., \& Gosseries, O. (2020, March 1). Near-Death Experience as a Probe to Explore (Disconnected) Consciousness. Trends in Cognitive Sciences. Elsevier Ltd. https://doi.org/10.1016/j.tics.2019.12.010 
Mills, P. J., Barsotti, T. J., Blackstone, J., Chopra, D., \& Josipovic, Z. (2020). Nondual Awareness and the Whole Person. Global Advances in Health and Medicine, 9, 216495612091460.

https://doi.org/10.1177/2164956120914600

Mondaini, N., Gontero, P., Giubilei, G., Lombardi, G., Cai, T., Gavazzi, A., \& Bartoletti, R. (2007). Finasteride 5mg and Sexual Side Effects: How Many of these are Related to a Nocebo Phenomenon? The Journal of Sexual Medicine, 4(6), 1708-1712. https://doi.org/https://doi.org/10.1111/j.1743-6109.2007.00563.x

Morin, E. (1995). Le vie della complessità. In G. Bocchi \& M. Ceruti (Eds.), La Sfida della Complessità (pp. 49-60). Milano, Italy: Fektrinelli.

Parnia, S., Spearpoint, K., de, V. G., Fenwick, P., Goldberg, D., Yang, J., ... Schoenfeld, E. R. (2014). AWARE-Awareness during Resuscitation-A prospective study. Resuscitation, 85(12), 1799-1805.

Penson, P. E., Mancini, G. B., Toth, P. P., Martin, S., Watts, G., Sahebkar, A., .. LBPMC. (2018). Introducing the "Drucebo" effect in statin therapy: a systematic review of studies comparing reported rates of statin-associated muscle symptoms, under blinded and open-label conditions. Journal of Cachexia, Sarcopenia and Muscle, 9(6), 1023-1033.

https://doi.org/10.1002/jcsm.12344

Piercy, M. A., Sramek, J. J., Kurtz, N. M., \& Cutler, N. R. (1996). Placebo response in anxiety disorders. Annals of Pharmacotherapy. SAGE Publications Inc. https://doi.org/10.1177/106002809603000917

Popper, K. R. (1972). Objective Knoweldge. Oxford, UK: Oxford University Press.

Popper, K. R., \& Eccles, J. C. (1977). The Self and His Brain. Berlin: Springer-Verlag.

Price, D. D., Finniss, D. G., \& Benedetti, F. (2008). A Comprehensive Review of the Placebo Effect: Recent Advances and Current Thought. Annual Review of Psychology, 59(1), 565-590. https://doi.org/10.1146/annurev.psych.59.113006.095941

Radin, D., Schlitz, M., \& Baur, C. (2015). Distant Healing Intention Therapies: An Overview of the Scientific Evidence. Global Advances in Health and Medicine, 4(Suppl), 67-71. https://doi.org/10.7453/gahmj.2015.012.suppl

Radin, D., Wahbeh, H., Michel, L., \& Delorme, A. (2021). Psychophysical interactions with a doubleslit interference pattern: Exploratory evidence of a causal influence. Physics Essays, 34(1), 79-88. https://doi.org/10.4006/0836-1398-34.1.79

Rainville, P., Carrier, B., Hofbauer, R. K., Bushnell, M. C., \& Duncan, G. H. (1999). Dissociation of sensory and affective dimensions of pain using hypnotic modulation. Pain, 82(0304-3959 (Print)), $159-171$.

Rief, W., \& Petrie, K. J. (2016). Can Psychological Expectation Models Be Adapted for Placebo Research? Frontiers in Psychology, 7, 1876. https://doi.org/10.3389/fpsyg.2016.01876

Ring, K., Valarino, E. E., \& Connecticut, U. (1998). Lessons from the light: What we can learn from 
the near-death experience. New York, NY, USA: Insight Books/Plenum Press.

Roe, C. A., Sonnex, C., \& Roxburgh, E. C. (2014). Two meta-analyses on noncontact healing studies. Explore: The Journal of Science and Healing, 11, 11-23.

https://doi.org/10.1016/j.explore.2014.10.001

Rutherford, B. R., Wall, M. M., Brown, P. J., Choo, T.-H., Wager, T. D., Peterson, B. S., ... Roose, S. P. (2017). Patient Expectancy as a Mediator of Placebo Effects in Antidepressant Clinical Trials. The American Journal of Psychiatry, 174(2), 135-142.

https://doi.org/10.1176/appi.ajp.2016.16020225

Schakel, L., Veldhuijzen, D. S., Crompvoets, P. I., Bosch, J. A., Cohen, S., Van Middendorp, H., ... Evers, A. W. M. (2019). Effectiveness of Stress-Reducing Interventions on the Response to Challenges to the Immune System: A Meta-Analytic Review. Psychotherapy and Psychosomatics, 88(5), 274-286. https://doi.org/10.1159/000501645

Solms, M., \& Panksepp, J. (2012). The "Id" Knows More than the "Ego" Admits: Neuropsychoanalytic and Primal Consciousness Perspectives on the Interface Between Affective and Cognitive Neuroscience. Brain Sciences, 2(2), 147-175. https://doi.org/10.3390/brainsci2020147

Spiegel, D. (2013). Tranceformations: hypnosis in brain and body. Depression and Anxiety, 30(15206394 (Electronic)), 342-352.

Stubenberg, L. (2018). Neutral monism. In N. Zalta, U. Nodelman, C. Allen, \& R. Lanier Anderson (Eds.), Stanford Encyclopedia of Philosophy (pp. 1-67). Stanford University, USA.

Tamburella, F., Moreno, J. C., Herrera Valenzuela, D. S., Pisotta, I., Iosa, M., Cincotti, F., ... Molinari, M. (2019). Influences of the biofeedback content on robotic post-stroke gait rehabilitation: Electromyographic vs joint torque biofeedback. Journal of NeuroEngineering and Rehabilitation, 16(1). https://doi.org/10.1186/s12984-019-0558-0

Tan, L. L., \& Kuner, R. (2021). Neocortical circuits in pain and pain relief. Nature Reviews Neuroscience 2021 22:8, 22(8), 458-471. https://doi.org/10.1038/s41583-021-00468-2

Taves, A. (2020). Mystical and Other Alterations in Sense of Self: An Expanded Framework for Studying Nonordinary Experiences. Perspectives on Psychological Science. https://doi.org/https://doi.org/10.1177/1745691619895047

Testoni, I., Facco, E., \& Perelda, F. (2017). Toward A New Eternalist Paradigm for Afterlife Studies: The Case of the Near-Death Experiences Argument. World Futures, 73(7), 1-15. https://doi.org/10.1080/02604027.2017.1357935

Tracey, I. (2010). Getting the pain you expect: mechanisms of placebo, nocebo and reappraisal effects in humans. Nature Medicine, 16(11), 1277-1283. https://doi.org/10.1038/nm.2229

Tressoldi, P., Facco, E., \& Lucangeli, D. (2017). On the primacy and irreducible nature of first-person versus third-person information. F1000Research, 6(99).

https://doi.org/10.12688/f1000research.10752.1 
Tressoldi, P., \& Storm, L. (2021). Anomalous Cognition: An Umbrella Review of the Meta-Analytic Evidence. Journal of Anomalous Experience and Cognition, 1(1-2). https://doi.org/10.31156/jaex.23206

Walach, H. (2020). Inner Experience - Direct Access to Reality: A Complementarist Ontology and Dual Aspect Monism Support a Broader Epistemology. Frontiers in Psychology, 11, 640. https://doi.org/10.3389/fpsyg.2020.00640

Walach, H., Tressoldi, P., \& Pederzoli, L. (2016). Mental, behavioural and physiological nonlocal correlations within the Generalized Quantum Theory framework. Axiomathes, 26(3), 313-328. https://doi.org/10.1007/s10516-016-9290-6

Velmans, M. (2021). Is the universe conscious? Reflexive monism and the ground of being. In E. Kelly \& P. Marshall (Eds.) Consciousness unbound: Liberating mind from the tyranny of materialism, Lanham, Maryland: Rowman \& Littlefield, pp. 175-228

Woollacott, M., \& Peyton, B. (2021). Verified account of near-death experience in a physician who survived cardiac arrest. EXPLORE, 17(3), 213-219. https://doi.org/10.1016/J.EXPLORE.2020.03.005

Zeidan, F., Martucci, K. T., Kraft, R. A., Gordon, N. S., McHaffie, J. G., \& Coghill, R. C. (2011). Brain mechanisms supporting the modulation of pain by mindfulness meditation. J.Neurosci., 31(1529-2401 (Electronic)), 5540-5548.

Zis, P., Hadjivassiliou, M., Sarrigiannis, P. G., Jenkins, T., \& Mitsikostas, D. (2018). Nocebo in chronic inflammatory demyelinating polyneuropathy; a systematic review and meta-analysis of placebo-controlled clinical trials. Journal of the Neurological Sciences, 388, 79-83. https://doi.org/https://doi.org/10.1016/j.jns.2018.03.009 